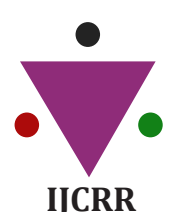

IJCRR

Section: Healthcare

Sci. Journal Impact

Factor: 6.1 (2018)

ICV: 90.90 (2018)

(c) (i) (s)

Copyright@IJCRR

\title{
Comparative Study of Frozen Section with Permanent Section at a Tertiary Care Centre in Southern Rajasthan
}

\author{
Pawan Nikhra', Kavita Gupta1, Quresh Bambora², Vardan Maheshwari³ \\ 'Assistant Professor, Department of Pathology, American International Institute of Medical Sciences, Udaipur, Rajasthan, India; ${ }^{2}$ Associate \\ Professor, Department of Surgery, American International Institute of Medical Sciences, Udaipur, Rajasthan, India; ${ }^{3 A s s o c i a t e ~ P r o f e s s o r, ~}$ \\ Department of Dentistry, American International Institute of Medical Sciences, Udaipur, Rajasthan, India.
}

\section{ABSTRACT}

Introduction: Frozen section diagnosis helps the surgeon to make an intraoperative decision regarding further management. Comparison of frozen section diagnosis and final histopathology report aids in assessing the degree of diagnostic accuracy of frozen section and also helps to identify the potential pitfalls.

Objective: To assess the degree of diagnostic accuracy of frozen section in a tertiary hospital in southern Rajasthan and to identify the potential causes of the discrepancy.

Methods: In this study total 197 frozen section cases were identified in 2 years. The intraoperative consultation results were compared with final histopathology diagnosis. Data were analyzed and concordance rate, discordance rate, sensitivity and specificity were calculated.

Results: The age group of the cases received ranged from 12-80 years with a male to female ratio 1.3:1. Of the 197 cases received, the majority of intraoperative consultations were sought from the head-neck region followed by breast and ovary. The common indications for frozen sections in our hospital were margin status, primary diagnosis and lymph node status. Out of the $66(33 \%)$ cases received for primary diagnosis, 31 (15.7\%) cases were diagnosed as benign and $35(17.7 \%)$ cases as malignant on frozen section. The frozen section report was concordant with final histopathology in 190 (96.4\%) cases and was discordant in $7(3.5 \%)$ cases with an overall diagnostic accuracy of $96.4 \%$.

Conclusion: The frozen section diagnostic performance at our centre appears satisfactory and is comparable with most other similar studies published in the literature. Discrepancies can be prevented by acquiring prior clinical information of the cases and more accurate sampling.

Key Words: Frozen section, Intraoperative consultation, Accuracy, Concordance, Permanent section, Margin assessment

\section{INTRODUCTION}

Frozen section was first introduced by William $\mathrm{H}$. Welch at John Hopkins hospital in the year $1891 .{ }^{1}$ Frozen section diagnosis has become a routine practice over the past 60 years. The principle of the frozen section is when the tissue is frozen; the water within the tissue turns into ice and acts as an embedding medium. ${ }^{2}$ Frozen section provides rapid diagnosis during surgery that allows the surgeon to make an intraoperative decision regarding further management. The intraoperative consultations are required for various reasons such as primary diagnosis (benign vs malignant), margin status, lymph node status (positive or negative for metastasis), assess adequacy for biopsy and various ancillary techniques.
The frozen section should not be used for surgeon curiosity or a preliminary report to the family in the recovery room. It is important to periodically review the frozen section report and compare it with the final paraffin section report so that potential causes of error can be identified and measures can be taken to rectify them. Long term monitoring of frozen section report helps pathologist to improve the quality of reporting.

The present retrospective study aims to assess the degree of diagnostic accuracy of frozen section in a tertiary hospital in southern Rajasthan and to identify the potential causes of the discrepancy.

\section{Corresponding Author:}

Kavita Gupta, Assistant Professor, Department of Pathology, American International Institute of Medical Sciences, Udaipur, Rajasthan, India; Email: drkavita0307@gmail.com

ISSN: 2231-2196 (Print)

Received: 23.07 .2020
ISSN: $0975-5241$ (Online)

Revised: 19.09 .2020
Accepted: 08.11 .2020
Published: 05.01 .2021 


\section{MATERIALS AND METHODS}

The present study was carried out in the Department of Pathology at American International Institute of Medical Sciences, Udaipur after approval of the institutional ethical committee (AIIMSUDR/2020/IEC/03). A total of 197 cases were identified in the duration of 2 years (2017-2019). For frozen section diagnosis fresh tissue was received from operation theatre without preservative. Representative areas from the tissue were sampled and were embedded on chuck using freezing media. Sections were cut under controlled temperature in a modern cryostat machine (Yorko; YSI-121). Slides were stained by rapid haematoxylin and eosin method. The remaining tissue was fixed in $10 \%$ buffered formalin and submitted for routine paraffin sectioning. The frozen reports were compared with the final histopathology reports available. If the frozen report was in agreement with the histopathology report then was considered as concordant or else was categorised as discordant. In all the discordant cases, causes for discrepancy were noted. The number of cases deferred was also noted with the reason for deferral.

The data was then analysed using SPSS software, Version 20.0 and parameters such as accuracy, sensitivity, specificity, positive predictive value and negative predictive value were determined.

\section{RESULTS}

In 2 years, the frozen section was performed on a total of 197 cases and was compared with the final conventional histopathology report (Figure 1\&2). The age group of the cases received ranged from 12-80 years with a male to female ratio $1.3: 1$. Of the 197 cases received, the majority of intraoperative consultations were sought from the head-neck region which contributed to $53.8 \%$ followed by breast $(35.5 \%)$ and ovary $(9.6 \%)$ (Table 1). Common indications for frozen sections in our hospital were margin status (122 cases, $61.9 \%$ ), primary diagnosis (66 cases, $33.5 \%$ ) and lymph node status ( 9 cases, $4.5 \%)$. Out of the $66(33.5 \%)$ cases received for primary diagnosis, $31(15.7 \%)$ cases were diagnosed as benign and $35(17.7 \%)$ cases as malignant on frozen section. The frozen section report was concordant with final histopathology in $190(96.4 \%)$ cases and was discordant in 7 (3.5\%) cases (Table 2) with an overall diagnostic accuracy of $96.4 \%$. The incidence of false-positive diagnosis was $0.5 \%$ and false-negative was 3.0\%. The frozen section technique in our hospital was $93.4 \%$ sensitive and $99.04 \%$ specific with a positive predictive value of $98.8 \%$ and a negative predictive value of $94.5 \%$ (Table 3 ). Of the two cases deferred, one was from the ovary and the other was from the oral cavity. Cause for deferral in ovary specimen was difficult interpretation due to poor morphology and freezing artefacts. Oral cavity specimen was deferred as it was sent in formalin.

\section{DISCUSSION}

Frozen section is a well-established procedure to assist the surgeon in determining the extent of surgery. However, it is technically challenging and has sampling issues; therefore not all institutes provide the facility for the same. When done with maximum accuracy can be a boon to the surgeon. The pathologist should be aware of the limitations of frozen reporting and should not hesitate to communicate with the surgeon in case of doubt. ${ }^{3-5}$ It is better to defer reporting in a difficult situation than to commit errors. In the present study, margin status was the most common indication for frozen section followed by primary diagnosis and lymph node status. However, some studies showed that the most common indication for the frozen section was primary diagnosis. ${ }^{3,6,7} \mathrm{In}$ our institute, we receive many head and neck malignancies in which the surgeon's area of maximum concern is adequate margin clearance. Adequate margin clearance is necessary not only to minimise the risk of recurrence but also to decide the further radiation protocols.

The overall diagnostic accuracy in our case was $96.4 \%$ which was comparable to various other studies in which accuracy ranged from $92.0 \%-98.6 \%$ (Table 4). ${ }^{8-10}$ The accuracy of frozen section in head and neck malignancies was found to be $98.1 \%$ which was equivalent to that reported by DiNardo et al $(98.3 \%)$ in a series of 420 cases. $^{11}$

In this study discordance rate was $3.5 \%$ in which 7 cases were incorrectly diagnosed. The false-negative diagnosis was given in 6 cases, however, one case was diagnosed false positive (Table 1). We find in literature; a discordant diagnosis rate ranging from $1.7-4.9 \% .{ }^{12}$ Out of 7 discordant cases 2 were from the oral cavity, 2 were from the ovary, 2 from lymph nodes and 1 belonged to the gastrointestinal tract. The reason for discordance as either sampling error or misinterpretation (Table 2). To avoid misinterpretation, the case must be thoroughly discussed with the surgeon before surgery. ${ }^{11,12}$ The pathologist should know the clinical, biochemical and radiological parameters of the patient; so that the findings of the frozen specimen can be correlated and the correct decision can be made. In case of any discrepancy or doubt; help of co-pathologist can be sought for. To prevent sampling error more sections can be taken from the specimen. But the limitations are its effect on specimen integrity during final grossing, delay in reporting and increase in expenses. Other potential causes of error in reporting may be due to tissue sectioning and staining which depends upon the method used for freezing, type of specimens received, quality of cryostat machine used and nature of the lesion. ${ }^{13-15}$ In the present study; the prevalence of deferred diagnosis $(1.0 \%)$ was comparable with other similar audits $(0.09-6.7 \%){ }^{8}$ Two cases were deferred; one from oral cavity sent for margin status and other from ovary sent for primary diagnosis. The oral cavity frozen section was deferred as the specimen was 
sent in formalin and ovarian frozen section was deferred because of difficulty in diagnosing the nature of lesion due to poor morphology and freezing artefacts. The final paraffin diagnosis in this case was well-differentiated Sertoli Leydig cell tumour. ${ }^{16}$ Deferral rate in various centres may vary due to technical expertise, type of specimen received and diagnostic acumen of the pathologist. Other parameters such as sensitivity (93.4\%), specificity (99.04\%), positive predictive value $(98.8 \%)$ and negative predictive value $(94.5 \%)$ were consistent with similar other studies (Table 3). ${ }^{3,16}$

\section{CONCLUSION}

Assessment of results of frozen section and final histopathology helps in monitoring the quality of the laboratory reports and also to assess the diagnostic capabilities of the pathologist. It is important to maintain the turnaround time for the frozen report which can be done by prior information of clinical details of the patient and good communication with the surgeon.

\section{ACKNOWLEDGEMENT}

The authors would like to thank our technicians Mr.Bhupendra Choudhary and Mr.Aziz Qureshi for good frozen sectioning and staining. The authors are also grateful to authors/editors / publishers of all those articles, journals and books from where the literature for this article has been reviewed and discussed.

\section{Financial support: Nil}

\section{Conflict of interest: None declared}

\section{REFERENCES}

1. Phulgirkar PP, Dakhure SD. The diagnostic accuracy of frozen section compared to routine histological technique - A comparative study. Int J Sci Res 2018; 3(3):88-92.

2. Spencer LT, Bancroft JD. Microtomy: paraffin and frozen sections. In: Suvarna SK, Layton C, Bancroft JD. Theory and practice of histological techniques. $7^{\text {th }}$ ed. Churchill Livingstone: Elsevier Health. 2012;125-138.
3. Hatami H, Mohsenifar ZH, Alavi SN. The diagnostic accuracy of frozen section compared to the permanent section: A single centre study in Iran. Iran J Pathol 2015; 10(4): 295-99.

4. Shrestha S, Lee MC, Dhakal H, Pun CB, Pradhan M, et al. Comparative study of frozen section diagnoses with histopathology. Med J NAMS 2009; 9(2):1-5.

5. Patil P, Shukla S, Bhake A, Hiwale K. Accuracy of frozen section analysis in correlation with surgical pathology diagnosis. Int J Res Med Sci 2015; 3:399-404.

6. Ackerman LV, Ramirez GA. The indications and limitations of frozen section diagnosis: A review of 1269 consecutive frozen section diagnosis. Br Med J 1959; 46(198):336-50.

7. Novis DA, Gephardt GN, Zarbo RJ. Inter-institutional comparison of frozen section consultation in small hospitals: a college of American Pathologists QProbes study of 18,532 frozen section consultation diagnoses in 233 small hospitals. Arch Pathol Lab Med 1996; 120(12):1087-93.

8. White VA, Trotter MJ. Quality assurance in anatomic pathology: Correlation of intraoperative consultation with final diagnosis in 2812 specimens. Abstract presented at the 96th annual meeting of the United States and Canadian Academy of Path. 2007.

9. Narang V, Goyal RC, Batta N, Garg B, Sood N. Utility of frozen section study in quality control of surgical pathology laboratory. Int J Path Res 2017; 6(2 Pt 2):467-70.

10. Selvakumar AS, Rajalakshmi V, Sundaram KM. Intraoperative frozen section consultation- an audit in a tertiary care hospital. Ind J Pathol Oncol 2018; 5(3):421-28.

11. DiNardo LJ, Lin J, Karageorge LS, Powers CN. Accuracy, utility, and cost of frozen section margins in Head and Neck cancer surgery. Laryngoscope 2000;110:1773-76.

12. Chbani L, Mohamed S, Harmouch T, El Fatemi H, Amarti A. Quality assessment of intraoperative frozen sections: An analysis of 261 consecutive cases in a resource-limited area: Morocco. Health Sci 2012;4(7):433-5.

13. Chandramouleeswari K, Yogambal M, Arunalatha P, Bose JC, Rajendran A. Frozen and paraffin sections- Comparative study highlighting the concordance and discordance rates in a tertiary care centre. J Dental Med Sci 2013; 12(5):26-30.

14. Mahe E, Ara S, Bishara M, Kurian A, Tauqir S, Ursani N. Intraoperative pathology consultation: error, cause and impact. Can J Surg 2013;56(3):13-8.

15. Patel R, Shah I, Goswami H. Correlation of Frozen section and routine histopathological findings in brain tumours. Int J Cur Res Rev 2017;9(20):35-8.

16. Maurya VP, Rana V, Kulhari K, Kumar P, Takkar P, Singh N. Analysis of intraoperative frozen section consultations and audit of accuracy: a two-year experience in a tertiary care multispeciality hospital in India. Int J Res Med Sci 2020;8(8):1-9.

Table 1: Organ wise analysis of total no. of cases

\begin{tabular}{|c|c|c|c|c|c|}
\hline Sr No. & Organ/Tissue & Total cases & Consistent diagnosis & False positive cases & False negative cases \\
\hline 1 & Breast & 38 & 38 & o & o \\
\hline 2 & Oral Cavity & 106 & 104 & o & 2 \\
\hline 3 & Ovary & 19 & 17 & 1 & 1 \\
\hline 4 & Soft tissue & 7 & 7 & o & o \\
\hline 5 & Lymph nodes & 18 & 16 & o & 2 \\
\hline 6 & Uterus & 3 & 3 & o & o \\
\hline 7 & GIT & 3 & 2 & o & 1 \\
\hline \multirow[t]{2}{*}{9} & Others & 12 & 12 & o & o \\
\hline & Total & 197 & 190 & 1 & 6 \\
\hline
\end{tabular}


Table 2: Discordant cases

\begin{tabular}{|c|c|c|c|c|c|}
\hline Sr No & Organ & Discordance type & $\begin{array}{l}\text { Frozen section diag- } \\
\text { nosis }\end{array}$ & $\begin{array}{l}\text { Paraffin section diag- } \\
\text { nosis }\end{array}$ & Cause of discrepancy \\
\hline 1 & Oral cavity & False negative & Margin clear & Positive margin & Sampling error \\
\hline 2 & Oral cavity & False negative & Verrucous hyperplasia & $\begin{array}{l}\text { Well differentiated squa- } \\
\text { mous cell carcinoma }\end{array}$ & Misinterpretation \\
\hline 3 & Ovary & False negative & $\begin{array}{l}\text { Benign ovarian neo- } \\
\text { plasm }\end{array}$ & Adenocarcinoma & Misinterpretation \\
\hline 4 & Ovary & False positive & $\begin{array}{l}\text { Benign ovarian neo- } \\
\text { plasm favour mature } \\
\text { teratoma }\end{array}$ & Torsion ovary & Misinterpretation \\
\hline 5 & Lymph node & False negative & Negative for metastasis & Positive for metastasis & Sampling error \\
\hline 6 & Lymph node & False negative & Negative for metastasis & Positive for metastasis & Sampling error \\
\hline 7 & GIT-Stomach & False negative & Margin clear & Positive margin & Sampling error \\
\hline
\end{tabular}

Table 3: Accuracy parameters in the present study and its comparison with various studies

\begin{tabular}{lccc} 
Accuracy parameters & Present study & Hatami et al $^{3}$ & Maurya et al $^{16}$ \\
Overall accuracy & $96.4 \%$ & $97.96 \%$ & $97.16 \%$ \\
Sensitivity & $93.4 \%$ & $92.95 \%$ & $98.64 \%$ \\
Specificity & $99.04 \%$ & $99.55 \%$ & $93.75 \%$ \\
Positive predictive value & $98.8 \%$ & $98.50 \%$ & $97.33 \%$ \\
Negative predictive value & $94.5 \%$ & $97.80 \%$ & $96.77 \%$ \\
\hline
\end{tabular}

Table 4: Comparison of concordance and discordance rate in various studies with present study

\begin{tabular}{lllll} 
Authors & Number of cases & Concordance rate & Discordance rate & Year of study \\
\hline Ackerman et $\mathrm{al}^{6}$ & 1269 & $98.0 \%$ & $2.0 \%$ & 1959 \\
${\text { Novis et } \mathrm{al}^{7}}$ & 18532 & $98.2 \%$ & $1.8 \%$ & 1996 \\
${\text { White et } \mathrm{al}^{8}}^{\text {Shrestha et al }}{ }^{4}$ & 2812 & $96.75 \%$ & $3.25 \%$ & 2007 \\
Vikram et al $^{9}$ & 404 & $94.6 \%$ & $5.4 \%$ & 2009 \\
Selvakumar et al $^{10}$ & 200 & $95 \%$ & $3 \%$ & 2017 \\
\hline
\end{tabular}

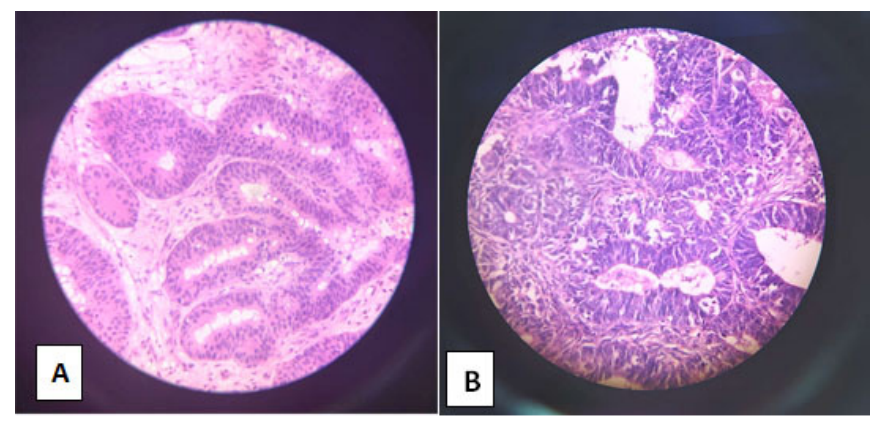

Figure 1: X400, H\&E. A. Frozen section of Endometrioid carcinoma of ovary, B. Paraffin section of Endometrioid carcinoma of ovary.



Figure 2: X400, H\&E. A. Frozen section of Mucinous carcinoma of breast, B. Paraffin section of Mucinous carcinoma of breast. 